\title{
Aplicação De Sensores Indutivos E Chaves Fim De Curso Em Ferramentas De Estampagem Como Forma De Segurança E Precisão Dimensional
}

\author{
Inductive Sensors Of Application And Limit Switches In Stamping \\ Tools As A Means Of Security And Dimensional Accuracy
}

Frank Ferreira da Silva1 ${ }^{1}$ Luciano Galdino², João Carlos Lopes Fernandes ${ }^{3}$

\begin{abstract}
1. Projetista na empresa Aliança Metalúrgica S.A. Graduado em Tecnologia Mecatrônica Industrial e graduando em Engenharia de Controle e Automação pela faculdade ENIAC. E-mail: frankfsilva@gmail.com

2. Professor de Física e Elementos de Máquina na Faculdade ENIAC. Mestre em Ciências Exatas e da Terra na área de Física Nuclear pela USP, especializado em Física pela USP e Licenciado em Matemática pela UNG. E-mail: lucianogaldino1@yahoo.com.br.

3. Professor pesquisador na Faculdade ENIAC. Doutor em engenharia biomédica pela UMC, Mestre em engenharia de computação pelo IPT/USP. Licenciado em ciências da computação pela USCS. E-mail: joao.carlos@eniac.com.br.
\end{abstract}

Resumo

Este artigo apresenta informações relevantes a respeito do processo de segurança no manuseio de ferramentas de estampagem e precisão dimensional de produtos, através da adaptação de sensores indutivos e chaves fim de curso. São descritos alguns tipos de chaves fim de curso de acordo com o mecanismo de acionamento e o princípio do funcionamento dos sensores de indução. Para exemplificar esta aplicação, foi utilizada uma ferramenta da empresa Aliança Metalúrgica S/A que gerou como produto final um "porta cadeado", onde a referência se dá no posicionamento durante o avanço do dispositivo, sendo assim o mesmo só será acionado quando o avanço não for correto, impedindo o funcionamento da prensa e possíveis acidentes.

Palavras-Chave: Estampagem. Segurança. Precisão. Sensores. Chaves fim de curso.

\begin{abstract}
This article presents relevant information regarding the process of safety in the handling of tools, stamping and dimensional precision products, through the adaptation of inductive sensors and limit switches. Are described some types of limit switches in accordance with the drive mechanism and the principle of the operation of the sensors of induction. To illustrate this application, was used a tool of company Metallurgical Alliance S / A that generated as a final product a "door lock",
\end{abstract}


where the reference is made in the positioning during the advance of the device, so the same can only be engaged when the feed is not correct, hindering the operation of the press and possible accidents.

Keywords: Stamping. Safety. Accuracy. Sensors. Limit switches.

\section{Introdução}

O objetivo deste artigo é demonstrar como e onde devem ser adaptados sensores e chaves fim de curso de forma eficaz, visando atender à segurança e precisão dimensional em ferramentas de estampagem de corte, dobra e repuxo. As características físicas e funcionais de alguns sensores e chaves também são abordadas neste trabalho visando apontar algumas opções de fixação e acionamento dos mesmos. Embora existam outros meios de se obter segurança e precisão dimensional, neste conteúdo será abordado exclusivamente à utilização de sensores indutivos e chaves fim de curso.

A importância de se garantir a segurança da ferramenta se dá em função de deficiências existentes nas prensas, “desbobinadores", "alimentadores", "bobinadores", além de prevenir de descuido e até imperícia do próprio operador da ferramenta. A eliminação da iminência de todo e qualquer risco à ferramenta de estampagem tem como objetivo evitar prejuízos, visto que os custos de ferramentas de estampagem são elevados, e reduzir os riscos à integridade física do operador.
A precisão dimensional do produto é essencial, pois este parâmetro é baseado nas exigências ou especificações determinadas pelo cliente ou projeto e a ferramenta de estampagem deve estar adequada para atender a essas especificações. Em situações onde os produtos obtidos pelos processos de estampagem requerem maior precisão, por se tratarem de componentes de alguma montagem ou função precisa, as variações no processo de estampagem acarretam em reprovações de lotes inteiros de produtos, agravados ainda mais quando se opera a ferramenta em prensa com grande capacidade de golpes por minuto.

Em virtude de se tratar de um assunto muito amplo, tanto com relação aos tipos de chaves fim de curso e sensores, como também aos diversos tipos de ferramentas de estampagem, este artigo utiliza como exemplo uma aplicação específica em uma ferramenta progressiva que resulta como produto final uma porta cadeado da empresa Aliança Metalúrgica. Vale ressaltar que aplicações semelhantes podem ser utilizadas nos diversos tipos de ferramentas de estampagem existentes e também utilizando uma série de chaves fim de curso e sensores. 


\section{Ferramentas de estampagem}

São dispositivos mecânicos fabricados e dedicados, em sua grande maioria, para produção seriada. Ao se referir a ferramentas de estampagem é importante saber que estas atendem ao processo de estampagem de corte, dobra e repuxo.

"Estampagem é o conjunto de operações com os quais, sem produzir cavacos, submetemos uma chapa plana a uma ou mais transformações com a finalidade de obtermos peças com geometrias próprias." (JÚNIOR e CAVERSAN, 2011).

Os mecanismos principais deste setor são as ferramentas de estampagem e estas só podem operar quando fixas a prensas, e seu bom desempenho depende de vários fatores como o correto dimensionamento físico da mesma, dimensionamento, mais aproximado possível, da carga necessária de trabalho, de um bom alimentador de tira ou peça, etc. Lembrando que "o dimensionamento adequado das forças para tais operações está restrito a "softwares" de simulação extremamente caros, o que torna muito difícil o cálculo correto das forças necessárias às ferramentas." (PRODTY, 2014).

As ferramentas são classificadas como simples, combinadas e progressivas. Estes termos estão relacionados com o processo de estampagem dentro da ferramenta.

\subsection{Ferramenta simples de estampagem.}

Uma ferramentas simples ou de estampo simples é aquela que: "executa uma operação apenas por vez". (PROVENZA, 1976, p.5.01), ou seja, consiste em obter o produto em apenas um golpe, ou uma prensagem, como por exemplo, uma ferramenta de dobrar, onde a dobra é processada por um único golpe (figura 1).



Fonte: Site da FR Projetos

No processo de dobra de uma peça é obtido o produto integral ou parcialmente, ou seja, um produto poderá ser obtido através de duas ou mais operações de estampagem simples. 


\subsection{Ferramenta combinada de}

estampagem.

Consiste em obter o produto em apenas um golpe, porém a ferramenta executa duas operações, como por exemplo, uma ferramenta de dobrar e furar ou uma ferramenta de cortar e furar (figura 2).

Figura 2: Desenho do conjunto de uma ferramenta de dobrar e furar. À direita encontra-se o produto, em vista frontal e lateral, com a furação e o corte efetuados.



Fonte: Provenza (1976)

\subsection{Ferramenta progressiva de} estampagem.

Segundo Provenza (1976, p. 5.01), ferramenta progressiva ou de estampo progressivo é quando: "São executadas operações que se sucedem com o avanço da tira", ou seja, consiste em obter o produto através de dois ou mais processos dentro de uma mesma ferramenta. A figura 3 apresenta uma ferramenta progressiva onde as características do produto são obtidas progressivamente até a conclusão do mesmo.

Figura 3: Ferramenta progressivo



Fonte: Site da Baldi Ferramentaria

Para que um estampo progressivo possa processar de forma adequada, o mesmo deve, além da prensa que é indispensável para se trabalhar com qualquer estampo, trabalhar auxiliado por alimentador de chapa ou tira.

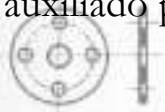

\section{Sensores indutivos}

Os sensores indutivos, são equipamentos utilizados para se detectar ou monitorar algo num processo ou equipamento industrial. "Os sensores indutivos apresentam princípio de funcionamento semelhante ao de um indutor”. (ROSÁRIO, 2013, p.69).

Eles têm seu funcionamento baseado no campo eletromagnético, ou seja, detectam materiais ferromagnéticos ${ }^{1}$. A detecção do objeto ferromagnético acontece quando este se

\footnotetext{
${ }^{1}$ São materiais de ligas metálicas com ferro que, quando submetidos a um campo magnético externo, alinham facilmente os seus dipolos atômicos com esse campo externo, tornando-se magnetizado (SHACKELFORD, 2008).
} 
aproxima do sensor a ponto de alterar o campo eletromagnético gerado na face sensora deste sensor, neste momento o sensor envia o sinal ao CLP (Comando Lógico Programável) que por sua vez executa alguma tarefa conforme programada a lógica do equipamento. A figura 4 ilustra este funcionamento.

Figura 4: Esquema de funcionamento do sensor indutivo.


Fonte: Site da Digel Elétrica.

Normalmente eles são construídos em material metálico com geométrica cilíndrica, tendo parte deste corpo cilíndrico uma rosca métrica (figura 5).

Figura 5: Sensor indutivo



Fonte: Site da Digel Elétrica

As diferenças entre os sensores indutivos se limitam a curso, eficiência e valores, pois o conceito de funcionamento é o mesmo para todos, independentemente de seu fabricante. Segundo o catálogo no site da empresa SENSE: “Os sensores indutivos são a opção de melhor custo-benefício para a automação de máquinas e equipamentos".

\section{Chaves fim de curso}

As chaves fim de curso, também chamadas de interruptores de posição, são equipamentos utilizados para se detectar ou monitorar algo num processo ou equipamento industrial. "Seu princípio de funcionamento é muito simples, trata-se de uma chave eletromecânica convencional que opera somente em "on/off" e que apresenta duas formas gerais de operação, normalmente aberta (NA) e normalmente fechada (NF)". (ROSÁRIO, 2013, p.63)".

Elas têm seu funcionamento baseado no acionamento mecânico, ou seja, por contato físico. O acionamento da chave acontece quando um mecanismo ou objeto toca a mesma, ocorrendo o fechamento ou abertura do circuito interno, dependendo da lógica ou tipo de chave utilizada. A construção interna, independente da construção externa das chaves, consiste na mesma construção apresentada na figura 6 .

Figura 6: Construção interna da chave fim de curso.



Fonte: Rosário (2013).

"Existe uma grande gama de aplicações que utilizam as chaves fim de curso e uma 
ampla variedade de formas mecânicas disponíveis no mercado”. (ROSÁRIO, 2013, p.2013).

A chave da figura 7 é acionada por uma alavanca articulada com uma roldana, onde o acionamento se dá no sentido radial da roldana.

Figura 7: Chave fim de curso



\section{Fonte: Site Digel Elétrica}

A chave da figura 8 é acionada por uma roldana fixa a um botão, onde o sentido do acionamento se dá no sentido do comprimento do mesmo.

Figura 8: Chave fim de curso



Fonte: Site Digel Elétrica

A chave da figura 9 é acionada por uma alavanca ajustável, articulada com uma roldana, onde o acionamento se dá no sentido radial da roldana.
Figura 9: Chave fim de curso



Fonte: Site Digel Elétrica

A chave da figura 10 é acionada por um botão, onde o acionamento se dá no sentido axial.

Figura 10: Chave fim de curso



Fonte: Site Digel Elétrica

Como já mencionado, há uma variedade muito grande de chaves com relação a sua forma construtiva e acionamento e foram apresentadas apenas as mais usuais.

"É bom e conveniente lembrar que a solução mais simples é sempre a melhor". (PROVENZA, 1976, p.1.03).

5. Segurança e precisão em ferramenta progressiva com a utilização de sensores indutivos e chaves fim de curso.

O processo de estampagem, assim como outros processos de fabricação, estão sujeitos a falhas. Essas falhas, de acordo com o seu grau, podem ter como consequência a quebra do ferramental, desvio dimensional e geométrico 
do produto obtido, perdas de matéria prima e até mesmo a perda da própria ferramenta.

Para inibir ou eliminar essas consequências pode-se utilizar ferramentas de estampagem com sensores indutivos e chaves fim de curso. Estes dispositivos são montados nas ferramentas com o intuito de monitorar o posicionamento de peças e da tira dentro da ferramenta, e caso este posicionamento não esteja dentro do esperado, a prensa não reinicia seu ciclo.

\subsection{O produto estampado na ferramenta} progressiva.

A aplicação dos sensores e chaves de fim de curso será exemplificado em uma ferramenta progressiva que tem como produto um porta cadeado da empresa Aliança Metalúrgica S.A (figura 11). Figura 11: Produto estampado (Porta
cadeado)



Fonte: Aliança Metalúrgica S.A.

A figura 12 apresenta um desenho técnico do mesmo produto com suas dimensões projetadas em vistas ortogonais.
Figura 12: Desenho técnico do porta cadeado de aço ABNT 10102.

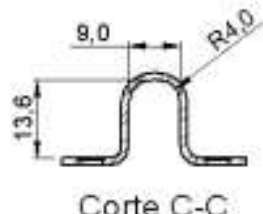

Corte $\mathrm{C}-\mathrm{C}$



Perspectiva isométrica

Fonte: Aliança Metalúrgica S.A.

Para demonstrar cada etapa do processo da ferramenta progressiva foi destacada a vista superior e a vista frontal da tira (Figura 13). É possível ver (da esquerda para a direita) que primeiramente são processados os furos, em seguida os recortes laterais, seguidos do recorte maior no meio da chapa metálica, logo após são feitos os escareados dos furos e por fim, a dobra e recorte do produto acabado. Como pode ser observado na figura 13 , os esforços necessários para a execução de cada operação são consideravelmente grandes. Essas forças são impostas também, além da tira, aos componentes da ferramenta responsáveis por cada operação.

\footnotetext{
${ }^{2}$ Tipo de aço classificado como baixo carbono (C) e que possuem $0,10 \%$ de $\mathrm{C}$ em sua composição (SHACKELFORD, 2008).
} 
Figura 13: Vista superior e frontal da tira do produto estampado com as indicações das forças em cada operação acompanhadas das forças de extração.



Fonte: Aliança Metalúrgica S.A.

$\mathrm{Na}$ ferramenta responsável pela obtenção deste produto cuidados devem ser tomados na operação de "escarear", pois o mau posicionamento da tira no momento do escareado pode acarretar, além da má formação do produto, a quebra do punção responsável pela operação. O escareado trata-se de um chanfro feito em todo o contorno do furo. Este escareado só é possível de ser executado em virtude de haver um furo antes de sua execução (figura 14).
Figura 14: Tira furada e escareada. A seta amarela indica o furo executado em uma operação anterior, enquanto a seta vermelha indica o mesmo furo já escareado.

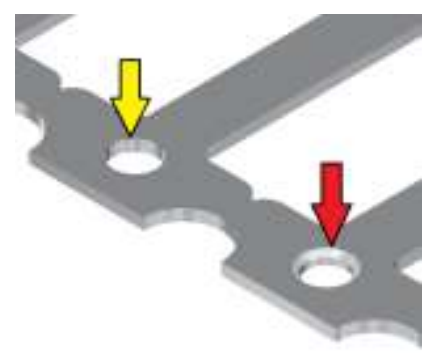

Fonte: Aliança Metalúrgica S.A.

Quando por algum motivo este "punção" “escareador" é prensado em uma parte da tira onde não há um furo, o esforço solicitado é muito maior, ocasionando a quebra do punção e/ou a obtenção de um produto irregular. A figura 15 ilustra o produto final defeituoso onde o punção prensou o escareado de forma excêntrica no furo, ocasionando a má formação do escareado.

Figura 15: Produto com falha no escareado.



Fonte: Aliança Metalúrgica S.A.

Além da má formação do produto, a solicitação à qual o punção estaria submetido seria superior à sua capacidade em virtude da força imposta pela prensa no mesmo, podendo ocasionar sua quebra. Não é possível precisar se a primeira ocorrência deste erro ocasionaria na quebra imediata do punção, ou seja, se a falha 
poderia ocorrer por várias vezes até a quebra o punção. Com isso, vários produtos sairiam com má formação, porém, se ocorrer a quebra do punção "escareador", vários produtos sairiam sem o escareado, conforme figura 16, o que seria um problema também, pois seria um desconformidade.

Figura 16: Produto sem escareado

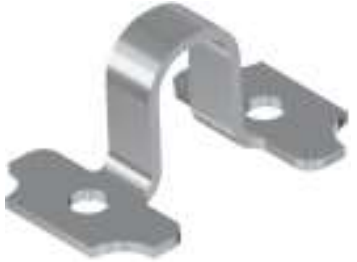

Fonte: Aliança Metalúrgica S.A.

No caso desta ferramenta, um fator que poderia ser associado aos problemas mencionados seria uma falha na alimentação da chapa, onde poderia haver um escorregamento da mesma ou desgaste do próprio alimentador. Para evitar tais problemas como a quebra da ferramenta e má formação do produto, pode ser utilizado um mecanismo verificador, onde o mesmo indicaria um posicionamento errado da tira antes do acionamento da prensa.

Enquanto a chapa é alimentada à prensa pelo alimentador, a prensa permanece aberta e em repouso, depois de alimentada a chapa, a prensa é acionada fazendo com que a ferramenta processe a estampagem, logo após a estampagem a prensa retorna à sua posição inicial para que a chapa seja alimentada novamente e este ciclo se repete por diversas vezes. Quando o avanço da chapa ou alimentação sofre variação, todos os problemas mencionados anteriormente ocorrem.
5.2 Atuação das chaves fim de curso e do sensor indutivo na ferramenta progressiva.

Foram implantadas na ferramenta progressiva algumas chaves de fim de curso e sensores indutivos que acionados mecanicamente, no caso das chaves, ou pela proximidade, no caso do sensor, denotam a presença de falha.

Os dois recortes nas laterais da tira, necessários para a formação do produto, são utilizados como referência de posicionamento para o mecanismo verificador (figura 17).

Figura 17: Destaque dos recortes laterais na tira (setas em vermelho).

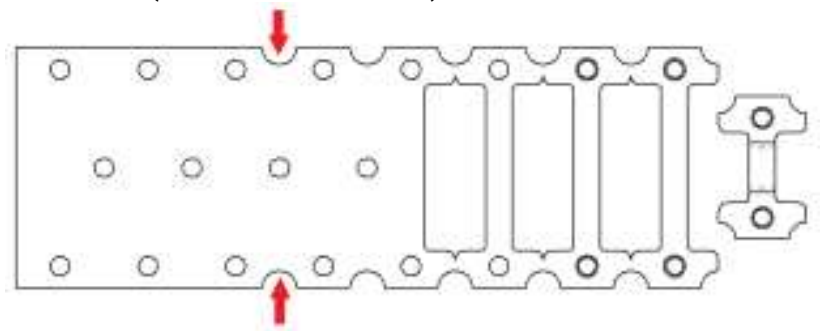

Fonte: Aliança Metalúrgica S.A.

A figura 18 mostra a ferramenta contemplada com o mecanismo verificador instalado estrategicamente de modo a verificar se o recorte da tira, mostrado na figura anterior está localizado no local adequado para que a prensa seja acionada. Neste mecanismo é utilizada uma chave fim de curso com alavanca articulada e roldana. 
Figura 18: Chave fim de curso adaptada na

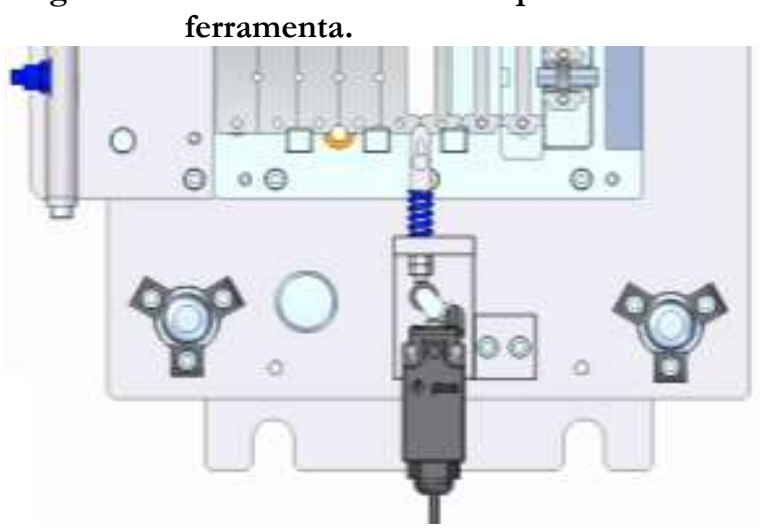

Fonte: Aliança Metalúrgica S.A.

$\mathrm{Na}$ figura 19 é possível observar um conjunto que, juntamente com a mola, forma o sistema acionador, onde em uma de suas extremidades há uma peça com uma geometria semelhante ao recorte lateral da tira para que ocorra o encaixe quando a tira estiver na posição correta. Já a outra extremidade (roscada) serve para acionar a chave quando a tira não estiver na posição correta e, assim, impedir o funcionamento da prensa. $\mathrm{O}$ acionamento desta chave, neste caso, denota o mau posicionamento da tira, ou seja, falha no avanço ou passo. Ao acionar esta chave a prensa fica impedida de funcionar, pois a chave está ligada ao circuito elétrico da prensa atuando como normalmente fechada, isto é, quando acionada abre o circuito impedindo a passagem da corrente responsável pelo comando de acionamento da prensa.
Figura 19: Acionador acoplado ao recorte da tira permitindo o funcionamento da prensa.



Fonte: Aliança Metalúrgica S.A.

$\mathrm{Na}$ figura 20 a chave se encontra acionada devido ao não acoplamento do acionador ao recorte da tira, assim a mola fica comprimida e a extremidade roscada aciona a chave, ou seja, houve variação no avanço da tira e, portanto, a prensa não funcionará.

Figura 20: Acionador não se acoplou ao recorte da tira impedindo acionamento da prensa



Fonte: Aliança Metalúrgica S.A.

A mesma aplicação pode ser feita outros diversos tipos de chaves fim de curso. A figura 21 demonstra a mesma aplicação utilizando chave fim curso do tipo botão. Nota-se que sua fixação é diferente comparada à chave fim de curso com alavanca articulada e roldana em virtude das diferentes características físicas de construção. 
Figura 2113: Chave fim de curso em repouso (não acionada).

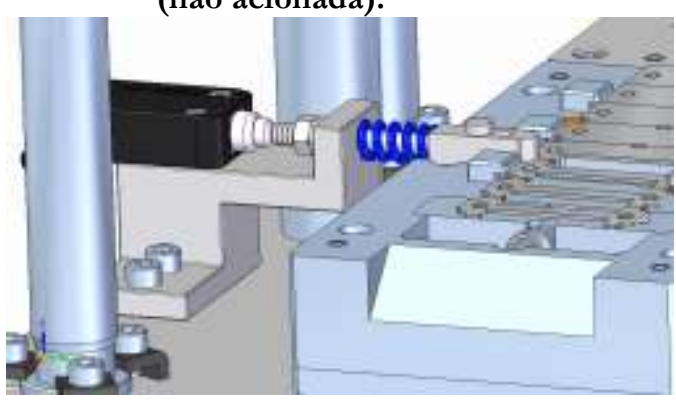

Fonte: Aliança Metalúrgica S.A.

A mesma aplicação pode ser feita também com o uso de sensores indutivos. A figura 22 exibe a ferramenta progressiva com o sensor indutivo acoplado.



Fonte: Aliança Metalúrgica S.A.

$\mathrm{Na}$ figura 23 é evidenciado o sensor indutivo de forma perpendicular à peça de acionamento do mesmo. Como mencionado anteriormente, o sensor indutivo atua de forma não mecânica, ou seja, não há contato físico com o corpo detectado, ele é acionado quando o corpo ferromagnético altera o campo magnético do indutor. Nota-se nesta figura que a extremidade roscada do acionador não está na linha do campo magnético do sensor, assim não ocorrerá interferência no campo e por isso ele não será acionado fazendo com que a prensa trabalhe normalmente.

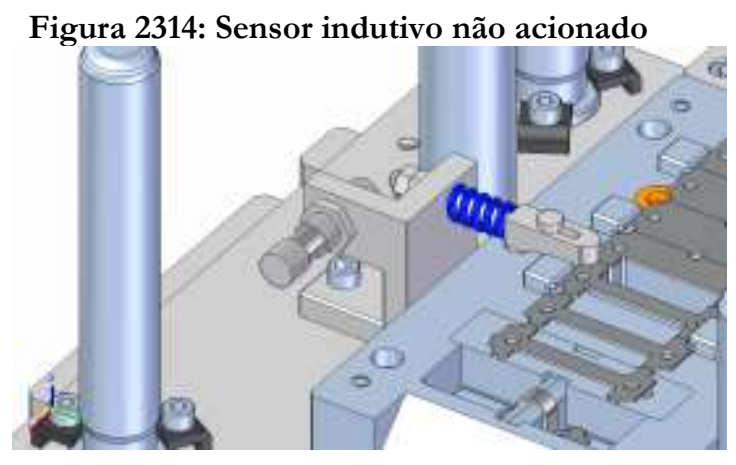

Fonte: Aliança Metalúrgica S.A.

$\mathrm{Na}$ figura 24 é possível notar o acionamento do sensor por parte do acionador, pois com a mola comprimida, a extremidade roscada do acionador interage com o campo magnético do sensor, ou seja, ocorre a interferência no campo magnético do sensor. Este acionamento impede o funcionamento da prensa, pois assim como a chave fim de curso, o sensor está ligado ao circuito elétrico da prensa atuando como uma chave normalmente fechada. Quando há alguma interferência no campo magnético do sensor, ele atua como uma chave aberta impedindo a passagem de corrente elétrica ao comando responsável pelo acionamento da prensa. 
Figura 24: Sensor indutivo acionado devido

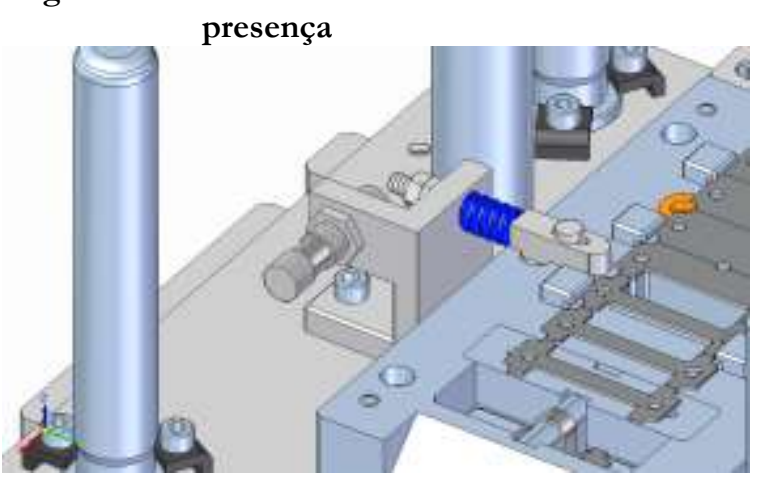

Fonte: Aliança Metalúrgica S.A.
Figura 26: Sensor indutivo não acionado devido encaixe do acionador na tira.

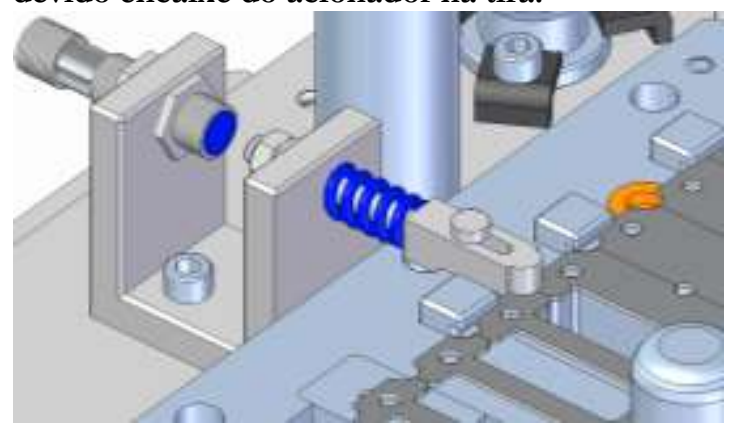

Fonte: Aliança Metalúrgica S.A.
A figura 25 demonstra outra maneira de posicionar o sensor indutivo, ao invés dele ficar perpendicular ao acionador como no exemplo passado, ele está posicionado paralelamente ao sensor.

Figura 25: Sensor indutivo paralelo ao

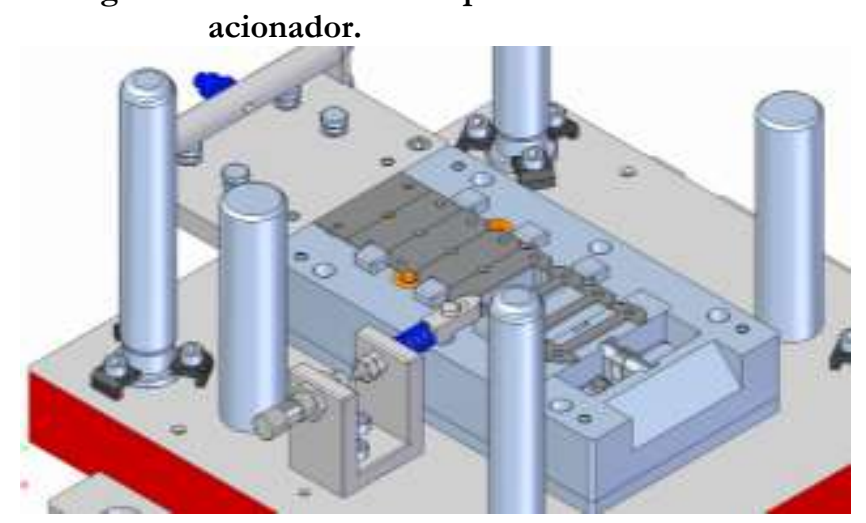

Fonte: Aliança Metalúrgica S.A.

Dessa maneira a interferência ocorrerá somente por aproximação linear, pois o sensor e o acionador estão alinhados. A figura 26 representa uma situação onde não ocorre a interferência, isto é, o acionador está a uma distância em que não ocorre o acionamento do sensor (ocorreu o encaixe do acionador na tira).
Já na figura 27, onde o acionador não se encaixa no recorte lateral da tira, a extremidade roscada dele fica a uma distância do sensor onde ocorre a interferência no campo magnético, fazendo com que acione o sensor e impeça o funcionamento da prensa.

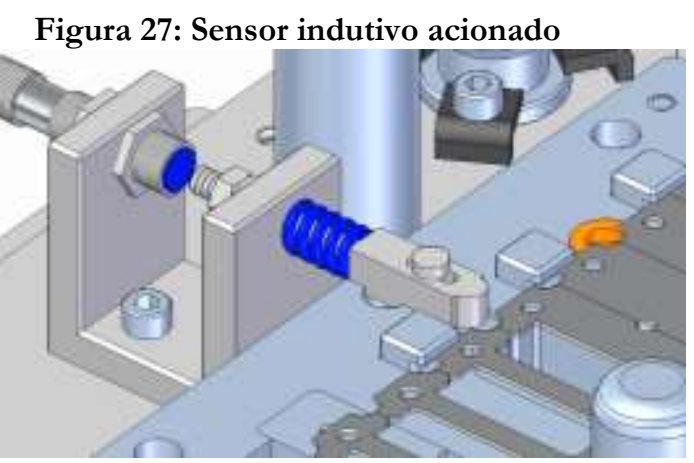

Fonte: Aliança Metalúrgica S.A.

Além das chaves e do sensor aqui demonstrados, há outros tipos de chaves e modelos de sensores que possam ser utilizados para o mesmo propósito, mas teriam o mesmo princípio de funcionamento e somente a forma de montagem seria alterada.

Todas as figuras referentes à ferramenta progressiva e ao produto porta cadeado fazem parte de um projeto original desse produto e 
foram cedidas gentilmente pela empresa Aliança Metalúrgica S/A.

\section{Conclusão}

Ficou evidenciado a importância de se garantir a precisão dimensional e a segurança de ferramentas de estampagem e que pequenas adaptações e inclusões de dispositivos simples, como chaves fim de curso e sensores indutivos, podem resultar em ótimos resultados que impedem erros comuns em processos repetidos como os de estampagens. As chaves fim de curso e sensores indutivos são comercialmente acessíveis e possuem baixo custo quando comparados aos prejuízos provenientes de falhas no processo de estampagem.

\section{Referências bibliográficas}

BALDI Ferramentaria. Disponível em < http://www.baldi.ind.br/>. Acesso em 20 de abril de 2015.

\section{DIGEL Elétrica Ltda - O que é um sensor} indutivo? Disponível em: $<$ http://www.digel.com.br/novosite/index.ph p?option $=$ com_content $\&$ view $=$ article $\&$ id $=67: 0$ -que-e-um-sensor-

indutivo\&catid $=42$ :tecnicos\&Itemid $=69>$.

Acesso em 18 de março de 2014.

FR Projetos - Projetos de ferramentas e dispositivos. Disponível em $<$ http://www.frprojetos.webnode.com.br/albu $\mathrm{m} /$ fotos-de-projetos/estampo-de-dobrajpg1/>. Acesso em 20 de abril de 2015.

JÚNIOR, Ivar B.; CAVERSAN, Elpidio G. Tecnologia de Estampagem. São Paulo: Centro Paula Souza, 2011. (Apostila).

PRODTY - Projeto de ferramentas (Aplicações), 2014. Disponível em < http://www.prodty.com.br/downloads/pdf/A plicacoes.pdf $>$. Acesso em: 13 de março de 2015.

PROVENZA, Francesco. Estampos 1. ed. 1. São Paulo: F. Provenza, 1976.

ROSÁRIO, João Maurício. Princípios de mecatrônica. ed. 1. São Paulo: Pearson Education do Brasil, 2013.

SENSE, Sensors \& instruments. Sensores indutivos. Disponível em $<$ http://www.sense.com.br/produtos/index/1 /33/Indutivos $>$. Acesso em 20 de abril de 2015.

SHACKELFORD, James F. Ciência dos Materiais. 6 ed. São Paulo: Person Prentice Hall, 2008. 